\title{
Uso de nuvens de palavras para identificação de pontos positivos e negativos do Programa Minha Casa, Minha Vida em Alagoas ${ }^{1}$
}

\section{Using wordclouds for identification of positive and negative aspects of My House, My Life Program in Alagoas}

\author{
Moraes, Odair Barbosa de '; Cavalheiro, Débora²; Abiko, Alex ${ }^{3}$ \\ 1 Universidade Federal de Alagoas, Campus Arapiraca - Av. Manoel Severino \\ Barbosa, Bom Sucesso 57309-005 Arapiraca - AL , Brasil, \\ odair.moraes@gmail.com \\ 2 Universidade Santo Amaro, debora.cavalheiro@gmail.com \\ 3 Universidade de São Paulo, alex.abiko@usp.br
}

\begin{abstract}
RESUMO
Na última década, o Brasil presenciou a retomada em grande escala de projetos de habitação social, com o Programa de Aceleração do Crescimento (PAC) e nele os programas Minha Casa Minha Vida (PMCMV) e Urbanização de Assentamentos Precários. No entanto, o processo de implementação destes programas tem se mostrado extremamente complexo. O PMCMV tem provido o acesso à moradia, mas não a cidade, com diversos projetos sem equipamentos urbanos e serviços adequados. O aprendizado a partir das ações realizadas tem sido uma meta entre os pesquisadores da área. Este artigo apresenta os resultados de uma pesquisa na qual foram realizados três estudos de caso em empreendimentos do PMCMV no estado de Alagoas, utilizando-se ferramentas de Avaliação Pós-Ocupação (APO). No presente artigo são apresentados os resultados das questões abertas e nota-se a importância do Programa quanto à posse da moradia para as classes de renda mais baixa, no entanto, aspectos negativos levantados ressaltam a necessidade ainda de projetos de habitação que, de fato, garantam o acesso à cidade e aos seus serviços.
\end{abstract}

Palavras chave: habitação social; Programa Minha Casa, Minha Vida; Alagoas.

\section{ABSTRACT}

In the last decade, Brazil has witnessed a large-scale resumption of social housing projects, with the Growth Acceleration Program (PAC) and within it the Minha Casa, Minha Vida (PMCMV) and Slums Upgrading Programs. However, the process of implementing these programs has been extremely complex. The PMCMV has provided access to housing, but not to the city, with several projects without urban equipments and adequate services. Learning from the actions carried out has been a goal among researchers. In this article based in a research, three case studies were carried out in PMCMV projects in the State of Alagoas, using Post-Occupancy Evaluation (APO) tools. In the present article the results of some questions are presented and

\footnotetext{
${ }^{1}$ MORAES, Odair Barbosa de; CAVALHEIRO, Débora; ABIKO, Alex. Uso de nuvens de palavras para identificação de pontos positivos e negativos do Programa Minha Casa, Minha Vida em Alagoas. In: II SIMPÓSIO NACIONAL DE GESTÃo E ENGENHARIA URBANA: SINGEURB, 2019, São Paulo. Anais... Porto Alegre: ANTAC, 2019.
} 
the importance of the Program in homeownership for lower income people is noticed. However, the negative aspects show that what is needed is more than a housing unit, but in fact, they need guarantee to access the city and its services.

Keywords: social housing; My Home, My Life Program; Alagoas.

\section{INTRODUÇÃO}

Desde 2009 o Brasil presenciou a retomada em grande escala de projetos de habitação social em todo o seu território. Com o Programa de Aceleração do Crescimento (PAC) e nele os programas Minha Casa Minha Vida (PMCMV) e Urbanização de Assentamentos Precários (PAC-UAP), o Brasil buscou retomar o enfretamento da questão habitacional que havia sido, de forma forçosa, assumida pelos Estados e Municípios de acordo com suas capacidades.

Os estudos da Fundação João Pinheiro (FJP) e do Centro de Estudo das Metrópoles evidenciam as duas categorias principais de carências habitacionais: o déficit quantitativo expresso pelo número de novas moradias e o déficit qualitativo, expresso pelo número de moradias construídas carentes de infraestrutura ou melhorias (FJP, 2018; MINISTÉRIO DAS CIDADES, 2007).

A primeira categoria de carência, objeto deste artigo, é tratada pelo PMCMV, que objetiva a construção de novas moradias com infraestrutura urbana, promovendo o acesso à casa própria. Os projetos do PMCMV tem demonstrado que o programa tem promovido o acesso a moradia, mas não a cidade, utilizando-se de terrenos periféricos, onde o preço da terra é mais barato, sem a devida infraestrutura urbana e serviços adequados, contribuindo assim para a segregação sócio-espacial e a criação de bolsões de pobreza e violência. Destacamos também a baixa qualidade das construções que levam a uma rápida deterioração do ambiente construído (ROLNIK et al, 2015). O PMCMV, apesar das grandes possibilidades de impacto positivo no déficit habitacional entrou em um movimento de construção de novos espaços urbanos com potencial de degradação e segregação urbana que repete os modelos já experimentados e cujas críticas e propostas foram documentadas por diversos pesquisadores.

Para o Estado de Alagoas os programas e projetos de habitação social tem importância vital. O Estado tem apresentado os piores indicadores sociais dentre os estados brasileiros. Estes indicadores se destacam tanto em termos sociais, mas também de infraestrutura e serviços urbanos, demonstrando as condições precárias, que se repetem em diferentes contextos urbanos, desde cidades de pequeno porte, como Palmeira dos Índios, até a capital, Maceió (URANI, 2005).

As possibilidades de reversão deste quadro dependem não somente de políticas sociais, mas também de investimentos em infraestrutura que possibilitem uma maior dinamização da economia do Estado (URANI, 2005). No campo habitacional, Alagoas tem recebido recursos nas áreas do PAC-UAP como também do PMCMV.

\section{MÉTODO}

A primeira fase do PMCMV permitiu a implantação de diversos conjuntos habitacionais no Estado de Alagoas, a exemplo dos estudos de caso deste trabalho: Residencial Jardim Royal (Maceió, com 2126 unidades na Faixa 2), Brisa do Lago (Arapiraca, com 1868 unidades na Faixa 1) e Edval Vieira Gaia (Palmeira dos Índios, com 451 unidades na Faixa 1). Todos pertencem a tipologia de casas/loteamentos e são situados nas franjas do perímetro urbano e ocupados em 2011. Nestes empreendimentos foram realizadas APOs e neste trabalho são apresentados os resultados das análises das questões abertas respondidas pelos usuários.

Foram elaboradas nuvens de palavras para as perguntas feitas sobre os pontos positivos e negativos da área total do residencial, bem como da unidade habitacional. Estes resultados foram discutidos levando-se em consideração as variáveis sociais e de situação da moradia anterior. 


\section{RESULTADOS E DISCUSSÕES}

As residências possuem apenas uma tipologia em cada um dos residenciais e apresentam como característica o padrão básico, constituídas de dois quartos, banheiro, cozinha, sala e serviço. Entre as plantas baixas das residências analisadas apenas a do Jardim Royal, ultrapassa os $40 \mathrm{~m}^{2}$ de área construída, em um lote de $126 \mathrm{~m}^{2}$, atendendo ao valor mínimo de lote $\left(125 \mathrm{~m}^{2}\right)$ de acordo com a Lei Federal 6.766 (BRASIL, 1979). A Tabela 1 apresenta a caracterização socioeconômica da amostra.

Tabela 1 - Caracterização dos domicílios pesquisados

\begin{tabular}{|c|c|c|c|c|}
\hline & & Jardim Royal & Brisa do Lago & Edval Vieira Gaia \\
\hline \multirow{2}{*}{$\begin{array}{l}\text { Renda da família } \\
\text { (Salários Mínimos(SM)) }\end{array}$} & Média & 2,28 & 1,10 & 1,12 \\
\hline & Mediana & 2,07 & 1,00 & 1,00 \\
\hline \multirow{8}{*}{$\begin{array}{l}\text { Grau de escolaridade } \\
\text { do chefe da família }\end{array}$} & Não respondeu & $2 \%$ & $23 \%$ & $5 \%$ \\
\hline & Não alfabetizado & $7 \%$ & $11 \%$ & $9 \%$ \\
\hline & $\begin{array}{l}\text { Fundamental } \\
\text { incompleto }\end{array}$ & $17 \%$ & $43 \%$ & $50 \%$ \\
\hline & $\begin{array}{l}\text { Fundamental } \\
\text { completo }\end{array}$ & $0 \%$ & $11 \%$ & $3 \%$ \\
\hline & $\begin{array}{l}\text { Ensino médio } \\
\text { incompleto }\end{array}$ & $60 \%$ & $7 \%$ & $14 \%$ \\
\hline & $\begin{array}{l}\text { Ensino médio } \\
\text { completo }\end{array}$ & $2 \%$ & $5 \%$ & $19 \%$ \\
\hline & $\begin{array}{l}\text { Superior } \\
\text { incompleto }\end{array}$ & $11 \%$ & $0 \%$ & $0 \%$ \\
\hline & $\begin{array}{l}\text { Superior } \\
\text { completo }\end{array}$ & $7 \%$ & $0 \%$ & $0 \%$ \\
\hline \multirow{2}{*}{$\begin{array}{l}\text { Quantas pessoas } \\
\text { moram na casa }\end{array}$} & Moda & 2,00 & 5,00 & 4,00 \\
\hline & Mediana & 3,00 & 4,00 & 4,00 \\
\hline \multirow{4}{*}{ Situação anterior } & Própria & $31 \%$ & $8,3 \%$ & $6 \%$ \\
\hline & Alugada & $54 \%$ & $71,5 \%$ & $65 \%$ \\
\hline & Com familiares & $16 \%$ & $16,0 \%$ & $24 \%$ \\
\hline & Não respondeu & $0 \%$ & $4,2 \%$ & $5 \%$ \\
\hline \multirow{4}{*}{ Situação atual } & Própria & $71 \%$ & $89,9 \%$ & $94 \%$ \\
\hline & Alugada & $27 \%$ & $3,4 \%$ & $2 \%$ \\
\hline & Com familiares & $2 \%$ & $4,0 \%$ & $3 \%$ \\
\hline & Não respondeu & $0 \%$ & $2,7 \%$ & $0 \%$ \\
\hline
\end{tabular}

Fonte: Os autores

É possível observar que os conjuntos residenciais localizados no interior (Arapiraca e Palmeira dos Índios) possuem os piores indicadores entre os três analisados. A quantidade de moradores por residência nesses dois conjuntos, tanto em valores médios e medianos, ultrapassa quatro pessoas. A renda familiar média gira em torno de ISM e o grau de escolaridade do chefe da família majoritariamente até o ensino fundamental incompleto

A nuvem de palavras identifica quais foram as palavras mais mencionadas pelos moradores nas entrevistas. No Quadro 1 notamos que o principal ponto positivo citado pelos residentes desses conjuntos é a posse da terra. A Tabela 1 mostra que a maioria dos beneficiários era originária de casas alugadas. Notamos que apesar da segurança ser destacada como um ponto negativo, a tranquilidade é ressaltada como ponto positivo e a disponibilidade de serviços e segurança são mencionados como aspectos negativos. 
Quadro 1 - Nuvem de Palavras - Pontos positivos e negativos do empreendimento

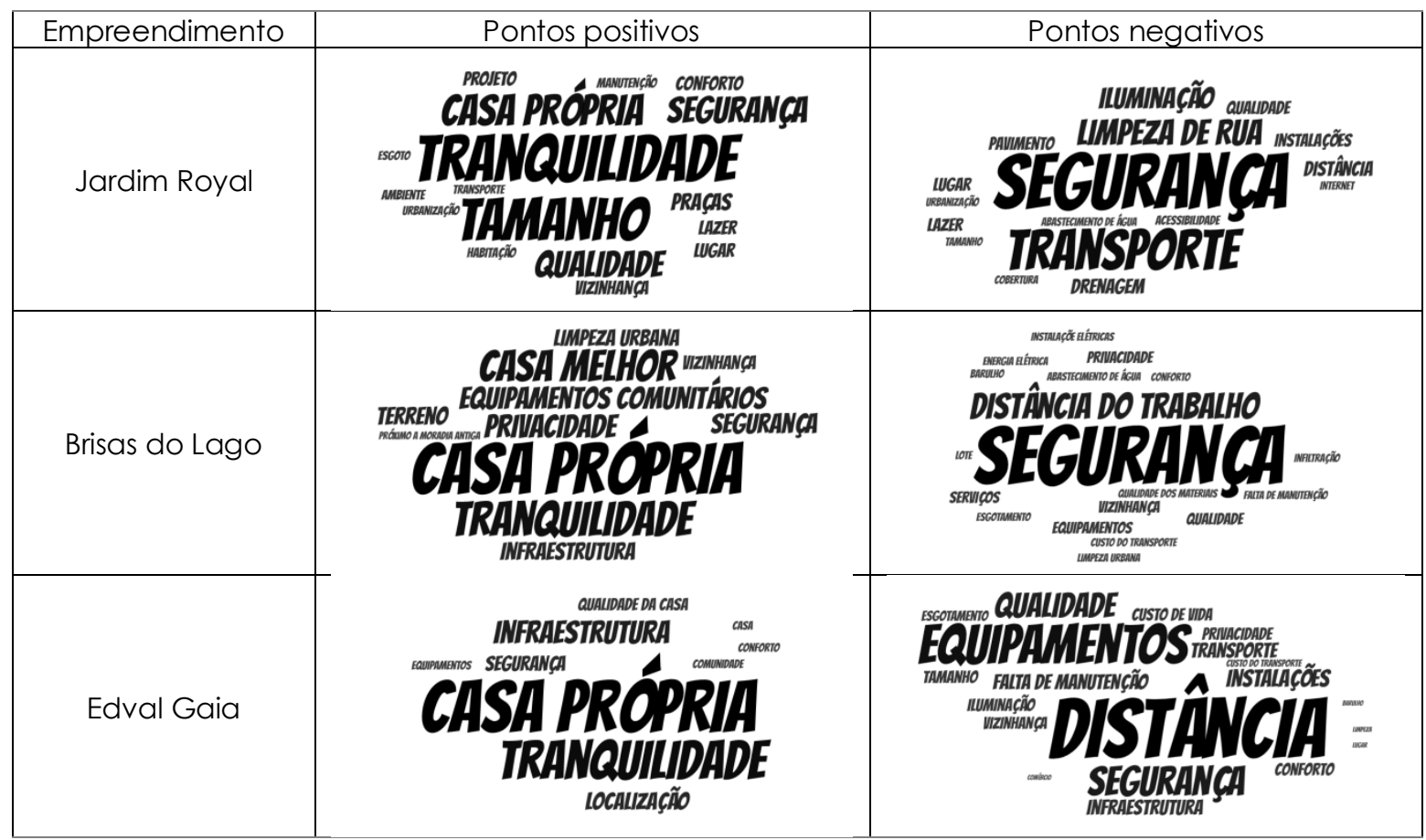

Fonte: Os autores

Quadro 2 - Nuvem de Palavras - Pontos positivos e negativos relacionados a Unidade Habitacional

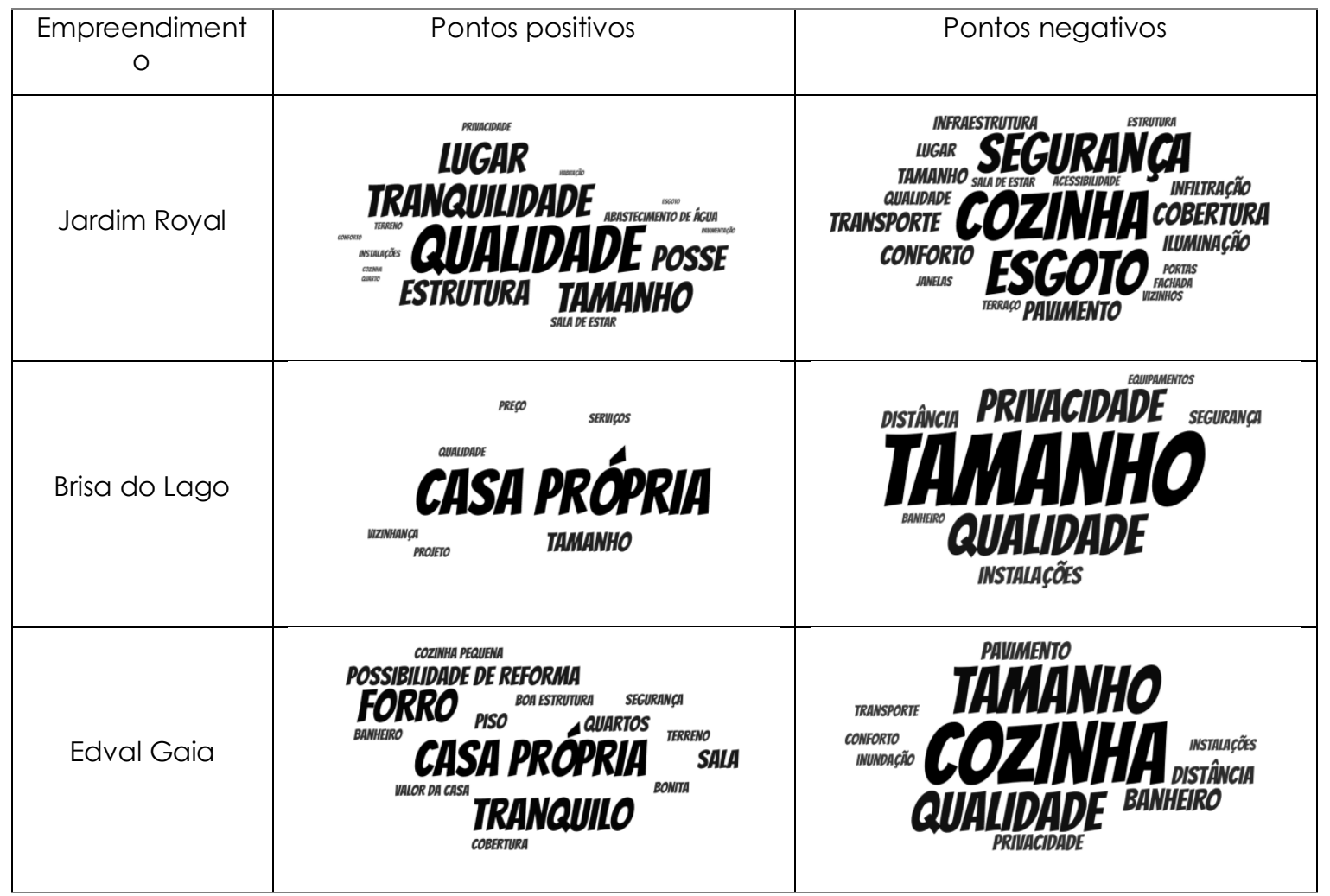

Fonte: Os autores

Quanto a unidade habitacional (Quadro 2), nota-se que no Jardim Royal, a qualidade e o tamanho das unidades, assim como a estrutura, tranquilidade e o fornecimento de água são considerados aspectos positivos. Porém, há um descontentamento em relação ao tamanho da cozinha e à segurança. 
No Brisa do Lago, também houve satisfação em relação ao tamanho das residências, mesmo com a possível superlotação. A posse da casa novamente foi considerada um ponto positivo. O tamanho, qualidade, instalações e a privacidade foram considerados aspectos negativos.

Por último, no Edval Vieira Gaia nota-se também a satisfação com a posse das casas, somado à tranquilidade do local. O tamanho da residência, mais especificamente da cozinha e do banheiro são aspectos negativos.

A localização, distante da zona urbana, tem refletido na mobilidade e os equipamentos públicos são insuficientes para a demanda dos usuários. Isto tem sido agravado pela falta de manutenção periódica, ocasionando em sua deterioração.

As questões fechadas levantadas na APO confirmam os apresentados nas nuvens de palavras. Observou-se que muitos dos moradores estão satisfeitos com a habitação atual, mas insatisfeitos com seu tamanho. Nota-se na Tabela 1, pelo número mediano de moradores por domicílio, que ao menos metade das moradias apresenta inadequação quanto ao número de moradores por quarto.

\section{CONSIDERAÇÕES FINAIS}

Os dados levantados nos três conjuntos habitacionais mostram que eles apresentam problemas similares quanto à moradia e a infraestrutura adotada. Dentre os principais problemas encontrados destacamos a localização, geralmente implantados fora da zona urbanizada, e a questão da segurança.

Como principal ponto positivo, para os conjuntos destinados a renda mais baixa, destaca-se a posse da moradia. Nota-se que a mudança para os conjuntos tornou-se um verdadeiro ponto de inflexão na vida dessas famílias, uma vez que a maioria vivia em imóveis alugados e após a mudança em torno de $90 \%$ moram em casas próprias.

Percebe-se que o PMCMV, teoricamente, combate o déficit quantitativo de moradias, no entanto, tem produzido ambientes, que mesmo diante das exigências de instalação de infraestrutura do Programa, ainda carecem de ligação e inserção no tecido urbano das cidades.

Destacamos, no entanto que apesar do Programa partir de premissas corretas, o processo de implementação tem se mostrado extremamente complexo e com diversos desvios, notadamente de localização desses empreendimentos. Os conflitos de interesses entre os atores e o desequilíbrio entre os seus papéis têm transformado possíveis soluções em problemas.

\section{REFERÊNCIAS}

BRASIL. Lei n. 6.766, de 19 de dez. de 1979. Parcelamento do solo urbano, Brasília,DF, dez 1979.

FUNDAÇÃO JOÃO PINHEIRO (FJP). Déficit Habitacional no Brasil 2015. Belo Horizonte: FJP. 2018. 78p.

MINISTÉRIO DAS CIDADES. CENTRO DE ESTUDOS DA METRÓPOLE. Assentamentos precários no Brasil urbano. Brasília: Ministério das Cidades, [2007?], 390p

ROLNIK, Raquel et al . O Programa Minha Casa Minha Vida nas regiōes metropolitanas de São Paulo e Campinas: aspectos socioespaciais e segregação. Cad. Metrop., São Paulo, v. 17, n. 33, p. 127-154, Mai 2015 . Disponível em

$<$ http://www.scielo.br/scielo.php?script=sci_arttext\&pid=S2236-

99962015000100127\&lng=en\&nrm=iso>. Acesso em 29 Abr. 2019.

URANI, André. Um diagnóstico socioeconômico do Estado de Alagoas a partir de uma leitura dos dados da Pesquisa Nacional por Amostra de Domicílios do IBGE (1992-2004). Instituto de Estudos do Trabalho e Sociedade. Rio de Janeiro, 2005. 